EMBRYARIDDLE
Aeronautical University

SCHOLARLY COMMONS
International Journal of Aviation, Aeronautics, and Aerospace

$10-9-2017$

\title{
How Law Enforcement Unmanned Aircraft Systems (UAS) Could Improve Tactical Response to Active Shooter Situations: The Case of the 2017 Las Vegas Shooting
}

\author{
Ryan J. Wallace \\ Polk State College, ryan.wallace@erau.edu \\ Jon M. Loffi \\ Oklahoma State University - Main Campus, jon.loffı@okstate.edu
}

Follow this and additional works at: https://commons.erau.edu/ijaaa

Part of the Aviation Safety and Security Commons, and the Law Enforcement and Corrections Commons

\section{Scholarly Commons Citation}

Wallace, R. J., \& Loffi, J. M. (2017). How Law Enforcement Unmanned Aircraft Systems (UAS) Could Improve Tactical Response to Active Shooter Situations: The Case of the 2017 Las Vegas Shooting. International Journal of Aviation, Aeronautics, and Aerospace, 4(4). https://doi.org/10.15394/ ijaaa.2017.1198

This Position Paper is brought to you for free and open access by the Journals at Scholarly Commons. It has been accepted for inclusion in International Journal of Aviation, Aeronautics, and Aerospace by an authorized administrator of Scholarly Commons. For more information, please contact commons@erau.edu. 
On October 1, 2017, alleged gunman Stephen Paddock covertly amassed an arsenal of 23 firearms and thousands of rounds of ammunition on the 32nd floor of the Mandalay Bay Hotel and Casino in Las Vegas, Nevada (Yan \& Farimi, 2017; Fonrouge, Celona, \& Fears, 2017). Later that night, Paddock knocked out the hotel room windows creating a sniper perch and unleashed a barrage of gunfire on an unsuspecting crowd of 22,000 country music concert goers gathered below, merely 500 yards away (Yan \& Farimi, 2017; "Las Vegas," 2017; "Police," 2017). His cache of firearms included several high-power variants including the .308-caliber AR-10 rifle, four Daniel Defense DDM4 rifles, three FN-15s, and other rifles made by Sig Saur" (Fonrouge, Celona, \& Fears, 2017, p. 1). Detectives would later discover that several weapons had been modified or altered with devices, referred to as bump stocks, to increase their rate of fire (Fonrouge, Celona, \& Fears, 2017). The carnage Paddock unleased lasted 9 to 11 minutes and killed 59 people [including himself] and injured a further 500 [the exact number of wounded vary between reports] ("Las Vegas," 2017; "Police," 2017). The attack was dubbed by several news outlets as "the deadliest attack in modern U.S. history" (Yan \& Farimi, 2017, p. 1; “Las Vegas,” 2017, p. 1; Keneally, 2017, p. 1)

\section{Problem}

During the shooting, law enforcement officers were placed at a severe disadvantage in precisely locating and tactically engaging the shooter.

\section{Purpose}

The purpose of this paper was to examine law enforcement and emergency services challenges in responding and suppressing an active shooter threat, based on the case of the October 1, 2017 Las Vegas assault. Several applications of unmanned aircraft systems that could have potentially aided in simplifying, hastening, or improving emergency response capabilities were presented This paper does not intend to criticize the law enforcement response to the incident, but rather to inform of possible alternative actions.

\section{Tactical Conditions}

The shooter was in a superior tactical position to effect maximum carnage while maintaining a position of relative security and anonymity. Presented are several contributing factors:

Densely-packed public space. With more than 22,000 attendees crowded into a tightly-confined public space, the environment was favorable to inflict 
maximum casualties (Chivers, Gibbons-Neff, \& Goldman, 2017). These conditions created the additional danger of victims being trampled as the crowd panicked and stampeded to escape or find cover from the assault.

Adverse environmental conditions. The assault location was relatively free of obstructions or placements that could provide adequate protective cover from the hail of high-powered bullets. Victims literally had few viable options to flee the danger (Chivers, Gibbons-Neff, \& Goldman, 2017).

The Loud ambient noise of the concert likely provided an initial masking or distortion of the onset of the attack, resulting in a briefly delayed reaction from victims. One report indicated that attendees heard "popping" or confused the gunfire with the sound of fireworks (Ho, 2017).

By initiating his attack during the hours of darkness, the assailant further added to the confusion and complicated emergency response. While the concert was illuminated by artificial lighting, the darkness likely delayed locating the victims, and complicated triage, medical treatment, and transport efforts.

Elevated position. The shooter's position was ideal for reconnoitering the concert crowd. His elevated position on the 32nd floor gave him an unrestricted field of fire, uninhibited by obstructions. "Mr. Paddock's position overhead gave him a vantage point over objects and obstacles that would typically protect people from bullets flying from a gunman at ground level" (Gibbons-Neff \& Goldman, 2017 , p. 1). Further, "He was also perched from a vantage point that increased the likelihood that even errant shots were more likely to strike someone than had he fired them from the ground level" (Chivers, Gibbons-Neff \& Goldman, 2017, p. 1). It appears the shooter's selected his position carefully. During the subsequent investigation, law enforcement officers discovered a note scrawled with calculations to maximize the lethality of his attack ("Note," 2017). Las Vegas Police Department Officer David Newton described the calculations:

I could see on it he had written the distance, the elevation he was on, the drop of what his bullet was gonna be for the crowd...so he had that written down and figured out so he would know where to shoot to hit his targets from there" ("Note," 2017, p. 1).

The attack similarly resembles the 1966 University of Texas attack, where Charles Whitman barricaded himself atop the 27th floor of a clock tower and randomly assailed people below (Ergenbright \& Hubbard, 2012). This historical 
shooting spree lasted approximately 1 hour and 34 minutes-likely in part due to the inaccessibility of the shooter's position (Ergenbright \& Hubbard, 2012).

Protected position. Unlike the vast majority of prior active shooter incidents, the shooter elected to stay barricaded in his room rather than carry out a moving assault (Blair \& Schweit, 2014). This gave the assailant access to his significant stockpile of weapons and ammunition - the quantity of which he would have been unable to carry in a mobile attack. This also provided him relative safety to retreat back into the room, if he received police sniper fire from the ground. "The angles, distances, and presence of thousands of people made it impossible [for police to safely return fire]" (Reid, 2017, p. 1). Robert Chamberlain, a member of the Las Vegas Police Department's Counter-Terrorism Task Force, explains, "You are firing 32 floors up, from 500 meters. So the trajectory of our rounds [...] even if we are accurate, they are going to go up into the ceiling, up into the next floor" (Reid, 2017, p. 1). Finally, it severely disadvantaged law enforcement officers by having to engage the shooter in a protected space, with unknown dangers on the assailant's terms.

Positional anonymity. While the shooter's static position may have highlighted his relative position, precisely locating exactly which room he was in proved somewhat difficult for law enforcement (Reid, 2017). Reportedly, the police required 72 minutes from the initial emergency call to pinpoint the shooter's exact location and secure the scene ("Police," 2017).

Police began searching the hotel's $29^{\text {th }}$ floor before determining the gunman was on the 32nd floor. The SWAT team utilized the alarm activated by smoke to determine Paddock's location. But it still took SWAT some 20 minutes from the time they arrived at the hotel to pinpoint the exact room Paddock was located in. ("Police," 2017, p. 1)

Tactical surprise. It was notable that Paddock's attack was planned and executed with complete secrecy. There was no known threat or initial warning, and the assailant was not flagged on any federal or state law enforcement database (Ho, 2017). Despite not having a criminal record, one unnamed federal law enforcement source indicated that Paddock was "known to local authorities" ("Stephen Paddock," 2017, p. 1). This vague description fails to clarify law enforcement's past interactions with Paddock. 
Extensive firepower. Without incurring suspicion, the shooter was able to smuggle 23 high-powered weapons up to his 32nd-floor suite by concealing them within 10 luggage containers (Fonrouge, Celona, \& Fears, 2017).

The selection and modification of the weapons further increased their lethality. The weapons selected by Paddock were composed primarily of highpowered, "AR-15-style" rifles, well-suited for the range of the planned attack (Chivers, Gibbons-Neff, \& Goldman, 2017, p. 1). At least one of the weapons was configured with an electronic scope, designed to increase firing accuracy (Fonrouge, Celona, \& Fears, 2017).

Some of the weapons were outfitted with a device known as a bump stock, a modification to semi-automatic firearms that uses the rifle's recoil to increase the rate of fire (Chivers, Gibbons-Neff, \& Goldman, 2017).

Additionally, the gunman used tripods for at least some of his weapons, which added firing stability. Tripods are "Special mounts designed to fit the underside of a rile and sit atop camera tripods allow the gunman to fire more accurately while standing” (Chivers, Gibbons-Neff, \& Goldman, 2017, p. 1).

Paddock utilized high-capacity magazine clips-capable of holding between 50 to 75 rounds--for at least some of his firearms. This enabled him to discharge the rifle for longer-period bursts without interrupting to reload (Fonrouge, Celona, \& Fears, 2017; Chivers, Gibbons-Neff, \& Goldman, 2017).

Las Vegas Police Department's Multi-Assault Counter-Terrorism Action Capabilities Officer Lieutenant Reggie Rader, acknowledged the substantial firepower Paddock brought to bear, stating "It did cause some challenges logistically, being outgunned like that" (Reid, 2017, p. 1).

Surveillance. Further complicating law enforcement's tactical response, Paddock placed several cameras both inside and outside his hotel suite, with one mounted in the suite door's peephole. Presumably, the cameras were set to observe police tactical responses and identify those approaching his position ("Las Vegas," 2017; Ho, 2017).

It is likely that this surveillance setup alerted Paddock to the initial security response. Once security officers arrived outside Paddock's hotel room, the assailant turned his attention to engaging these first responders, firing shots through the door and striking one officer in the leg ("Police," 2017). 
Succinctly, the assailant carefully planned and executed a lethal, indiscriminate firearm attack from a semi-anonymous, protected and elevated position on a densely-packed crowd of unsuspecting victims in an open field at night. He was equipped with highly-capable, modified armaments designed to inflict maximum damage and was prepared to engage in a prolonged and sustained attack. He was fully prepared to counter, engage, or repel law enforcement tactical efforts to subdue him through electronic monitoring and brute firepower.

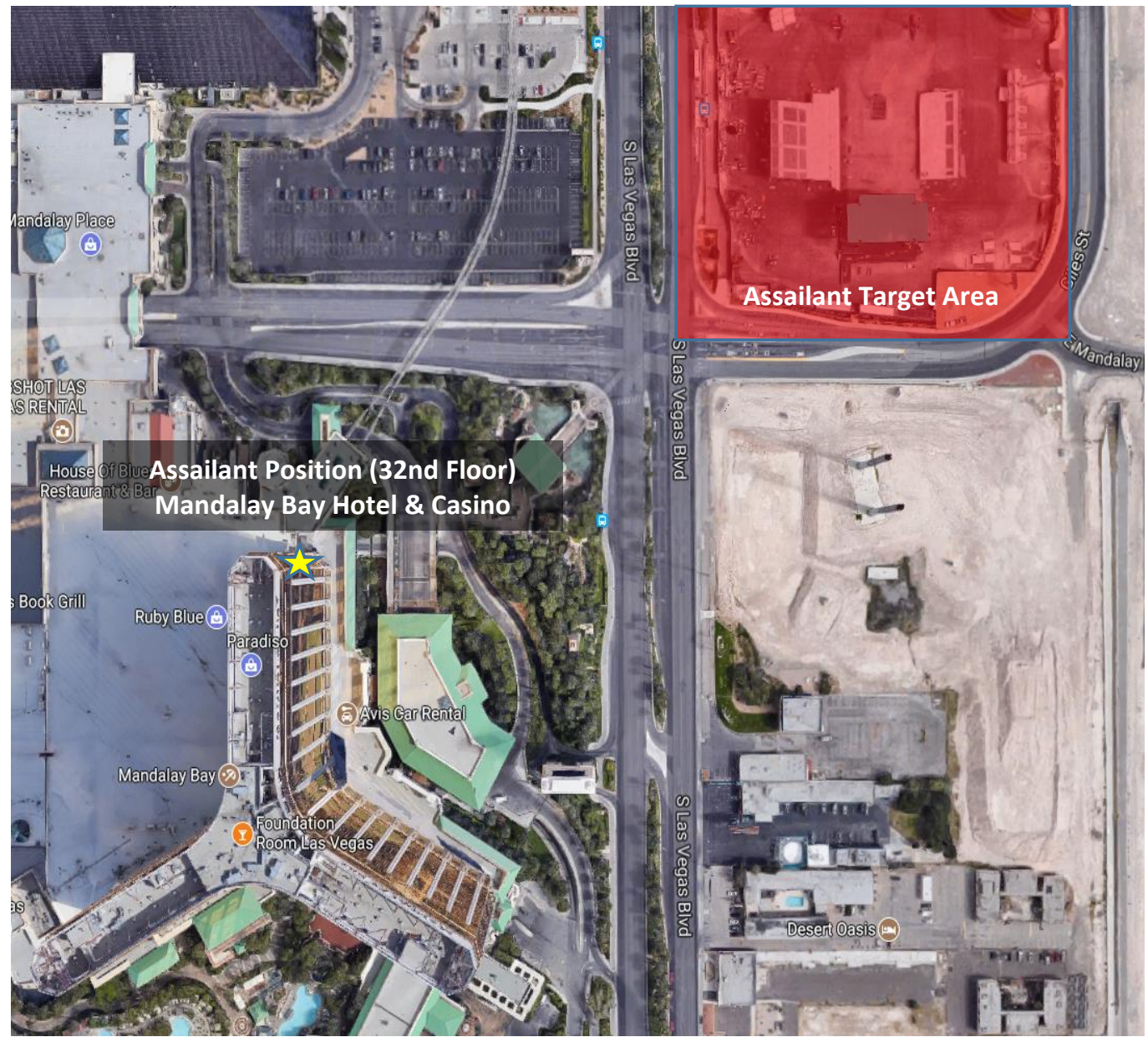

Figure 1. Google Maps display of assailant position and target area.

\section{Proposed Solution}

In the aftermath of the attack, at least one terrorism expert is claiming that the emergency response would have benefitted from the employment of unmanned aircraft systems. Brian Levin, Director of the Center for the Study of Hate and Extremism at Cal State University-San Bernardino, explained: 
Think about how useful a drone might have been if we have situations like this [Las Vegas shooting] now for large events... You have a guy on the 32nd floor [of a hotel], a drone could have provided real-time intelligence and surveillance to what's going on...Y You could have a drone up in two minutes in Las Vegas and fired an incendiary device into [the shooter's room-if he had weapons of mass destruction, you're going to wish you had a drone (Margaritoff, 2017 p. 1; Gazzar, 2017, p. 1; Reagan, 2017, p. 1)

Levin's suggestion is not without merit. Unmanned aircraft could likely have aided police in solving several tactical problems presented by the Paddock shooting.

Adept Intelligence Gathering. Marks (2017) describes the advantages of unmanned aircraft use [author emphasis added to UAS applications specifically relevant to the Las Vegas shooting]:

Other applications for which they [unmanned aircraft] are used include reconnaissance such as intelligence and gathering information, traffic observation, event and VIP security situations, crowd control, and hostage/terrorist situations as well as tactical and SWAT operations. Surveillance use includes reconnaissance missions prior to armed entry, gaining intelligence in hostage/terrorism situations and any number of other situations where an eye in the sky would be useful. (p. 34)

Adequately equipped unmanned aircraft could likely have collected vital intelligence to aid law enforcement in more accurately assessing the nature of the threat presented by the shooter. Aided by high-fidelity zoom cameras, such as the Zenmuse Z-30 or similar device, officers could have evaluated the number of assailants, types of weapons, and even pinpointed the location of the shooter using altitude and GPS information.

Bypass Surface Barriers. The unique capabilities of unmanned aircraftparticularly multi-rotor systems, allow operators to approach elevated or difficult to reach positions with ease. Areas that would typically be unpassable or inaccessible on the ground could be quickly accessed and evaluated from an unmanned aircraft. Murphy and Cycon (1999) state, "A small VTOL system would provide officers with the ability to see over and beyond large structures such as buildings without being hampered by ground terrain...[it] enhances situational 
awareness and extends law enforcement reach around buildings, terrain and other obstacles" (p. 1, 7).

Tactical Surprise \& Distraction. Following the initiation of Paddock's attack, it was highly likely that he expected law enforcement to intervene in short order. As evidenced by his placement of camera devices on the hallway approaches to his hotel suite, it can be surmised that he anticipated a conventional intervention, with law enforcement or SWAT officers breaching his door in the exact manner they did during the incident. What Paddock may not have anticipated is the unconventional use of unmanned aircraft to reconnoiter or actively impede his efforts.

Had Las Vegas law enforcement officers launched an unmanned aircraft it could have served not only as an intelligence gathering platform, but also a tactical distraction, drawing Paddock's attention away from the vulnerable crowd. It is not unreasonable to conclude that such an unexpected aerial intruder would have drawn fire from the shooter. It is this critical action that pivots the perpetrator's initial advantage in favor of the law enforcement, as the shooter's response to an unanticipated threat hands law enforcement tactical initiative. Moreover, such a distraction initiated during the heat of the attack would likely have provided the critical seconds necessary for more victims to find cover or escape, thereby reducing the lethality of Paddock's assault.

Additionally, UAS could be equipped with bright strobing LED lights that could be used as distraction tools. Such a configuration could temporarily blind the perpetrator or potentially obscure his view of the target area, forcing him to engage the unmanned aircraft rather than continue the assault.

Minimize Tactical Personnel Exposure. One of the chief benefits of unmanned aircraft is that they can be operated from a standoff distance, in relative safety from tactical threats. Murphy and Cycon (1999) explain, "Reconnaissance, surveillance, and target acquisition is performed without exposing a human point man to danger: range finding and target designation allow close coordination with supporting air and ground assets while minimizing fratricide and collateral damage" (p. 7).

While some argue that traditional airborne assets can fulfill the same function, there is prior anecdotal evidence to suggest that police helicopter pilots and crewmembers are potential and viable targets for an active shooter. During the 1966 University of Texas assault, police launched an aircraft commanded by Lieutenant Marion to conduct surveillance of the tower. The aircraft would confirm 
that Whitman was the sole sniper on the tower's observation deck. During the assault, however, the shooter reportedly fired upon Lee's aircraft, forcing Lee to reposition to a safe distance (Ergenbright \& Hubbard, 2012).

Additional Tactical Options. While the International Association of Chiefs of Police (IACP) has "strongly discouraged" equipping unmanned aircraft with weapons, there may be a reason to evaluate the viability of equipping UAS with non-lethal equipment to provide additional tactical options to the incident commander (IACP, 2012, p. 2). Murphy and Cycon (1999) suggest that UAS platforms could be equipped to deliver tear gas or smoke canisters. While some states, such as North Dakota, have embraced weaponizing unmanned aircraft with non-lethal devices for law enforcement functions, most other states have not.

\section{Conclusion}

While it is pure speculation to determine if the aforementioned tactical options may or may not have aided law enforcement officials, it is clear that those tactical options were either unavailable or not considered during the 2017 Las Vegas attack.

According to Gettinger (2017), 347 state and local public safety agencies have acquired unmanned aircraft. Based on Gettinger's (2017) findings, the Las Vegas Metro Police Department (LVMPD) was not among the agencies listed. That is not to say that the department is ignorant of the technology. According to an Unmanned Systems Experts (2016) press release, the company partnered with the LVMPD to test and present UAS-centric alternatives to vehicular accident scene investigation and reconstruction. Indeed, the state of Nevada is rife with local UAS resources and expertise, with the Las Vegas-based Nevada Institute of Autonomous Systems having been designated by the Federal Aviation Administration as one of the nation's six officially recognized UAS test sites (Nevada, 2017).

Law enforcement agencies should not discount the potential applications and benefits of unmanned aircraft systems to support tactical functions, emergency response, as well as normal operations. Los Angeles Sheriff Jim McDonnell understands the value of UAS, stating,

The (unmanned aircraft system) is too important as a public-safety tool to ground. I will not face the loved ones of a victim whose life could have been saved by our ability to deploy UAS. I cannot imagine meeting with a spouse or parent of a fallen deputy and say, yes, we could have done more. (Margaritoff, 2017, p. 1). 
Steve Soboroff, President of the Los Angeles Board of Police Commissioners agrees, saying, "Law enforcement did a phenomenal job [responding to the Las Vegas attack] but it absolutely makes the case for restricted, specific use of a drone" (Margaritoff, 2017, p. 1).

As with any resource, unmanned aircraft are not a panacea nor do they offer an immediate solution for active shooting situations, but they do provide unique capabilities to add yet another tool for law enforcement agencies to use in response. 


\section{References}

Blair, J.P. \& Schweit, K.W. (2014). A study of active shooter incidents in the United States between 2000 and 2013. Retrieved from https://www.fbi.gov/file-repository/active-shooter-study-2000-2013-1.pdf

Chivers, C.J., Gibbons-Neff, T. \& Goldman, A. (2017). Gunman's vantage point and preparations opened the way for mass slaughter. New York Times. Retrieved from https://www.nytimes.com/2017/10/02/us/las-vegas-massshooting-weapons.html

Ergenbright, C.E. \& Hubbard, S.K. (2012). Defeating the active shooter: applying facility upgrades in order to mitigate the effects of active shooters in high occupancy facilities (Thesis). Naval Postgraduate School, Monterey, California. Retrieved from https://calhoun.nps.edu/bitstream/handle/ 10945/7337/12Jun_Ergenbright_Hubbard.pdf?sequence=1\&isAllowed=y

Fonrouge, G., Celona, L. \& Fears, D. (2017). The 'tricked out' guns Las Vegas shooter used in the massacre. New York Post. Retrieved from http://nypost.com/2017/10/03/the-tricked-out-guns-las-vegas-shooterused-in-massacre/

Gazzar, B. (2017). Why some say Las Vegas mass shooting proves LA law enforcement should use drones. Daily News. Retrieved from http://www.dailynews.com/2017/10/03/why-some-say-las-vegas-massshooting-proves-la-law-enforcement-should-use-drones/

Gettinger, D. (2017). Public safety drones. Center for the Study of the Drone at Bard College. Retrieved from http://dronecenter.bard.edu/files/2017/04/ CSD-Public-Safety-Drones-Web.pdf

Ho, S. (2017). Fifty-nine dead as Mandalay Bay Las Vegas shooting becomes worst in U.S. history. Time. Retrieved from http://time.com/4964649/lasvegas-shooting-music-festival/

International Association of Chiefs of Police Aviation Committee. (2012). Recommended guidelines for the use of unmanned aircraft. IACP. Retrieved from http://www.theiacp.org/portals/0/pdfs/ IACP_UAGuidelines.pdf 
Keneally, M. (2017). 47 guns, loaded high-capacity magazines found in Vegas shooter's hotel suite and Nevada home. ABC News. Retrieved from http://abcnews.go.com/US/guns-loaded-high-capacity-magazines-foundvegas-shooters/story?id=50228093

Las Vegas shooting: Stephen Paddock fired for 9 to 11 minutes, police say. (2017). WPTV News. Retrieved from http://www.wptv.com/news/national/ las-vegas-shooting-stephen-paddock-fired-for-9-to-11-minutes-police-say

Margaritoff, M. (2017). Should we let police use drones post emergencies such as the Las Vegas Shooting. The Drive. Retrieved from http://www.thedrive.com/aerial/14837/should-we-let-police-use-dronespost-emergencies-such-as-the-las-vegas-shooting

Marks, K. (2017). Every agency can use unmanned aircraft systems (UAS). Police Fleet Manager. Retrieved from http://www.hendonpub.com/ police_fleet_manager/articles/2017/0102/every_agency_can_use_unmann ed_aircraft_systems_ua

Murphy, D. \& Cycon, J. (1999). Applications for mini VTOL UAV for law enforcement. Proceedings Vol 3577, Sensors, C3I, and Training Technologies for Law Enforcement. DOI: http://dx.doi.org/10.1117/12.336986

Nevada Institute for Autonomous Systems. (2017). Who we are. Retrieved from http://nias-uas.com/

Note in Las Vegas gunman's hotel room included details of bullet trajectory. (2017). CBS News. Retrieved from https://www.cbsnews.com/news/lasvegas-gunman-stephen-paddock-note-hotel-room-details-of-bullettrajectory/

Police took 72 minutes from first emergency call to reach Las Vegas shooter. (2017). Fox News. Retrieved from http://www.foxnews.com/us/2017/10/ 03/police-took-72-minutes-from-first-emergency-call-to-reach-las-vegasshooter.html

Reagan, J. (2017). Could police drones help stop mass violence. Drone Life. Retrieved from https://dronelife.com/2017/10/04/police-drones-helpcurtail-mass-shootings/ 
Reid, T. (2017). How the Las Vegas shooter foiled a well-drilled counterterrorism plan. Reuters. Retrieved from https://www.reuters.com/ article/us-lasvegas-shooting-plan/how-the-las-vegas-shooter-foiled-a-welldrilled-counter-terrorism-plan-idUSKBN1CA29N

Stephen Paddock: What we know about Vegas shooter, 'high states gambler'. (2017). Fox News. Retrieved from http://www.foxnews.com/us/2017/ 10/02/stephen-paddock-suspected-las-vegas-gunman-stashed-weapons-inroom-police-say.html

Unmanned Systems Experts. (2016). Unmanned Experts works with Las Vegas Metropolitan Police Department to demonstrate unmanned aircraft systems role in accident analysis [Press Release]. Retrieved from https://unmannedexperts.com/wp-content/uploads/Press-Release-UMEXLas-Vegas-Forensic-Mapping-Project-final-160726.pdf

Yan, H. \& Farimi, F. (2017). Las Vegas killer fired at airport fuel tank. CNN. Retrieved from http://www.cnn.com/2017/10/05/us/las-vegas-shootinginvestigation/ 